\title{
Milton and Galileo would back BMJ on free speech
}

\section{Arguments, crazy ideas and open communication are the lifeblood of science.}

Sir - Your News story "Medical journal under attack as dissenters seize AIDS platform" (Nature 426, 215; 2003) was a fair report of researchers' objections to rapid responses being posted on the website of the British Medical Journal (BMJ) by people who are sceptical about a link between AIDS and HIV. As editor of the $B M J$, however, I find it disturbing to see scientists arguing for restrictions on free speech. Surely open communication and argument is a fundamental value of science?

John Milton put the argument better than anybody in 1643, in his pamphlet Areopagitica. "Give me," he wrote, "the liberty to know, to utter, and to argue freely according to conscience, above all liberties. ... [W] ho ever knew Truth put to the worse, in a free and open encounter? ... Yet is it not impossible that she [truth] may have more shapes than one ... [I]f it come to prohibiting, there is not aught more likely to be prohibited than truth itself; whose first appearance to our eyes, bleared and dimmed with prejudice and custom, is more unsightly and unplausible than many errors ... Where there is much desire to learn there of necessity will be much arguing, much writing, many opinions; for opinion in good men is but knowledge in the making."

We should never forget Galileo being put before the inquisition. It would be even worse if we allowed scientific orthodoxy to become the inquisition.

I'm not arguing that those who doubt the link between HIV and AIDS are right, but I want to keep our threshold for posting rapid responses as low as possible.

How, I'm legitimately asked, does this fit with an editorial code I have drafted saying: "Editors should take all reasonable steps to ensure the accuracy of the material they publish." My first reaction is that perhaps "accuracy" is the wrong word to use. As editors we receive thousands of manuscripts containing millions of assertions. We can't possibly check every "fact", and distinguishing fact from opinion is not as straightforward as it sounds.

The answer, I think, lies in transparency. Our rapid responses are clearly unfettered debate full of crazy ideas, false logic, and unreadable, mis-spelt prose as well as some literary and scientific gems. What you see is what you get. In contrast, original articles have been as rigorously peer-reviewed as we can manage, with the recognition that peer review itself is a deeply flawed process.

Your News story states: “The dispute crystallizes the conflict in the Internet era between a journal's desire to experiment with open electronic debate, and its fundamental obligation to its readers to provide them with authentic information." I don't agree that there is a conflict. The beauty of the electronic world is that we can have no-holds-barred debate alongside greater selectivity. On our website you can do a search that includes or excludes rapid responses. I suggest that those who want to see the world as it is - rather than how they would like it to be - include rapid responses in their search.

Richard Smith

BMA House, Tavistock Square,

London WC1H 9JR, UK

\section{X-ray clues to viability of loop quantum gravity}

Sir - The unification of quantum mechanics with gravity is the most pressing question in theoretical physics today. However, experimental feedback to the theorists has been sorely lacking. Astrophysicists are now beginning to probe the behaviour of gravity at quantum (microscopic) scales.

For example, Igor G. Mitrofanov (Nature 426, 139; 2003) described a possible constraint on a leading theory, loop quantum gravity, based on the polarization of high-energy radiation from astrophysical sources. The high-energy photons have to travel cosmological distances to reach us, allowing small effects of quantum gravity to reveal themselves. This specific constraint depends on the reported detection of polarization from a $\gamma$-ray burst, which has yet to be confirmed, hence Mitrofanov cautioned readers to await confirmation of this measurement before concluding that loop quantum gravity is not viable.

There is no need to wait. The constraint on the polarization of $\gamma$-rays applies equally to the polarization of $\mathrm{X}$-rays, for which there are 30-year-old measurements. The X-ray polarization of the Crab nebula, a thousand-year-old remnant of an exploded star, was first measured by Novick and collaborators ${ }^{1}$ in 1972 and confirmed by a different instrument four years later ${ }^{2}$. The observed $\mathrm{X}$-ray polarization from the Crab nebula is in strong conflict $\left(\chi<10^{4}\right)$ with the predictions of loop quantum gravity, if the effects of quantum gravity depend linearly on photon energy.

Philip Kaaret

Harvard-Smithsonian Center for Astrophysics, 60 Garden St, Cambridge, Massachusetts 02138, USA

1. Novick, R. et al. Astrophys. J. 174, L1-L8 (1972).

2. Weisskopf, M. C. et al. Astrophys. J. 208, L125-L128 (1976).

\section{Return of bone archives is a loss to humanity}

Sir - As a member of the panel that published the Palmer report supporting the principle of repatriation of ancestral remains ("Bone archives face prospect of dispersal" Nature 426, 109; 2003), but also as the sole author of a statement of dissent, I argue that competing concerns must be weighed carefully on a case-by-case basis.

There must be a balance between the concerns of claimant communities on the one hand and, on the other, the loss to humanity resulting from wholesale return on request. It is clear to me that this balance will be destroyed if the return of human remains on request becomes the order of the day.

There is a strong case for the retention of human remains in the scientific collections of museums and university departments. Research into collections at the Natural History Museum in London over recent years has enabled surgeons to explore improved surgical techniques on damaged knee joints. It has increased our understanding of diverse human groups' responses to malaria, tuberculosis and other diseases, and has trained forensic anthropologists in methods which they then used to help identify bodies found in Bosnia's mass war graves.

The benefits that these collections provide to humanity are not sufficiently recognized in the Palmer report. Its recommendations that there should be return on request from claimant communities or individuals within those communities are tantamount to mandatory repatriation.

Neil Chalmers

The Natural History Museum, Cromwell Road, London SW7 5BD, UK

\section{correspondence}

Contributions to Correspondence may be submitted to corres@nature.com. They should be no longer than 500 words, and ideally shorter. Published contributions are edited. 